\title{
La editorial Gallach y su contribución a la industria cultural española. Recuperación y análisis de su catálogo
}

\author{
Juan Miguel Sánchez Vigil
}

María Olivera Zaldua *

Artículo recibido:

19 de agosto de 2013.

Artículo aceptado:

19 de noviembre de 2013.

\section{Resumen}

El estudio de la historia de la edición en España desde las empresas que conforman y han conformado el sector está por realizarse. En el caso que nos ocupa se investiga sobre la contribución que hizo la editorial Gallach, una de las pioneras en Barcelona a finales del siglo XIX, a la industria cultural española. Se recupera parte de su catálogo a partir del estudio de sus publicaciones y de los fondos de cuatro bibliotecas (Nacional de España, Nacional de Cataluña, Ateneo de Madrid y Ateneo de Barcelona). Se analiza asimismo la influencia de esta editorial y de su fundador, José Gallach Torras, en la creación y desarrollo de la prestigiosa editorial Calpe, a su vez origen de la magna Espasa-Calpe,

Los dos autores pertenecen a la Universidad Complutense de Madrid, España. (jmvigil@ccinf.ucm.es); (molivera@ucm.es)

INVESTIGACIÓN BIBLIOTECOLÓGICA, Vol. 28, Núm. 63, mayo/agosto, 2014, México, ISSN: 0187-358X. pp. 51-83 
la más antigua de las editoriales en activo ya que se remonta al año 1860 .

Palabras clave: Documentación Editorial; Edición; Editorial Calpe; Editorial Gallach; Historia de la Edición; Instituto Gallach; José Gallach Torras.

\section{Abstract}

The Gallach publishing house and its contribution to Spanish cultural life: reassembly and analysis of its catalogue

Juan-Miguel Sánchez-Vigil and María Olivera-Zaldua

A study of the history of Spanish publishing focusing on the publishing houses has yet to be carried out. This paper examines the contributions to Spanish culture of the Editorial Gallach, one of the pioneer publishing enterprises in Barcelona, which began operations near the end of the nineteenth century. A considerable portion of its catalogue has been reassembled by locating books it published in the National Library of Spain, the National Library of Catalonia, the Ateneo of Madrid and the Ateneo of Barcelona. Researchers also assessed the influences of this publishing house and that of its founder José Gallach Torras, specifically with regard to the founding and growth of the prestigious Calpe publishers, which in turn gave rise to Espasa-Calpe, Spain's oldest publishing company whose ongoing operations date to 1860 .

Keywords: Publishing documentation; Publication; Editorial Calpe; Editorial Gallach; History of Publishing; Instituto Gallach: José Gallach Torras.

\section{INTRODUCCIÓN}

Claborar la historia de la edición española es una tarea harto complicada dedicadas a la industria cultural por excelencia. Hasta ahora se han llevado a 
cabo trabajos de carácter general, ${ }^{1}$ y otros no menos interesantes dedicados específicamente a las editoriales, entre ellas La España Moderna, ${ }^{2}$ Aguilar; ${ }^{3}$ Calleja, ${ }^{4}$ Calpe ${ }^{5}$ o Seix Barral. ${ }^{6}$ Por consiguiente, nos encontramos ante un campo de investigación amplio y de gran interés dentro de la documentación editorial, y por extensión de la historia del libro.

La editorial Gallach, con casi un siglo de historia, es una de las más desconocidas a pesar de su intensa actividad y de su contribución a la creación de Calpe, la más popular en el primer tercio del siglo pasado, base de Espasa-Calpe, con implantación en México y Argentina. Gallach fue fundada en Barcelona en la última década del siglo XIX y tuvo una larga trayectoria hasta que en 1979 fue adquirida por el grupo Océano. Desarrolló dos etapas, la primera entre 1890 y 1918, año en que sus fondos pasaron a formar parte de Calpe, creada por Nicolás María Urgoiti, y la segunda a partir de 1924 con el nombre de Instituto Gallach.

La empresa evolucionó en un contexto propicio debido al auge de las instituciones vinculadas al libro y a la creación de los organismos defensores de los intereses de editoriales e imprentas, entre ellos el Instituto Catalán de las Artes del Libro y el Centro de la Propiedad Intelectual. En apenas un lustro se llevaron a cabo grandes eventos nacionales e internacionales y en todos ellos tomó parte Gallach: VI Congreso Internacional de Editores organizado en Madrid el año 1908 por la Asociación de Librería de España, Primera y Segunda Asamblea Nacional de Libreros y Editores celebradas en junio de 1909 y en mayo de 1910, Primer Congreso de las Artes del Libro de 1911, y la creación de la Federación Española de las Artes del Libro en 1912. En esas dos décadas José Gallach alcanzó gran prestigio entre sus colegas y fue confeccionando un catálogo de referencia que sería la base para la apertura de Calpe, como veremos más adelante.

Es objeto de este artículo estudiar los orígenes de la editorial Gallach, definir su lugar en la historia de la edición española, reconstruir la biografía de

1 Véase Hipólito Escolar, "El libro y la lectura en el siglo XX", en La edición moderna. Siglos XIX y XX, Madrid: Pirámide, 1996; Jesús A. Martínez Martín (dir.), Historia de la edición en España (1836-1936), Madrid: Marcial Pons, 2001; Xavier Moret, Tiempo de editores. Historia de la edición en España, 1939-1975, Barcelona: Destino, 2002; Sergio Vila-Sanjuán, Pasando página, Barcelona: Destino, 2003; Juan Miguel Sánchez Vigil, La edición en España, Gijón: Trea, 2009.

2 Véase Juan Antonio Yeves, La España Moderna, Madrid: Libris, 2002.

3 Véase María José Blas Ruiz, Aguilar. Historia de una editorial y de sus colecciones literarias en papel biblia (1923-1986), colab. de José Luis Sánchez de Vivar Villalba, pról. de Luis Alberto de Cuenca, Madrid: Librería del Prado, 2012.

4 Julio Berrio, Anastasio Martínez Navarro, Carmen Colmenar y Miryam Carreño, La editorial Calleja, un agente de modernización educativa en la restauración, Madrid: Uned, 2002.

5 Véase J. M. Sánchez Vigil, Calpe, paradigma editorial, Gijón: Trea.

6 Manuel Llanas y Antonio Lozano, Seix Barral. Nuestra historia, Barcelona: Seix Barral, 2011 
su fundador y recuperar parte de su catálogo. Para ello se ha revisado la bibliografía sobre la edición en España, se ha consultado el archivo particular del fundador de Calpe, Nicolás María Urgoiti; se han revisado los catálogos de cuatro bibliotecas de prestigio (Nacional de España, Nacional de Cataluña, Ateneo de Madrid y Ateneo de Barcelona) y se han analizado numerosas publicaciones de la propia editorial en colecciones públicas y privadas, entre ellas el periódico Mi Revista. Una vez recopilada y procesada la información se ha redactado el texto, obteniendo las conclusiones que resumen la aportación de Gallach a la historia de la edición española.

\section{Orígenes de la editorial Gallach}

La editorial Gallach tuvo su origen en el deseo de José Gallach Torras de poner en marcha un negocio de producción y distribución de libros, en un periodo de cambio en la industria propiciado por las nuevas tecnologías. Gallach nació en Barcelona el 30 de marzo de 1872, hijo del impresor del mismo nombre del que aprendió las artes gráficas (Figura 1).

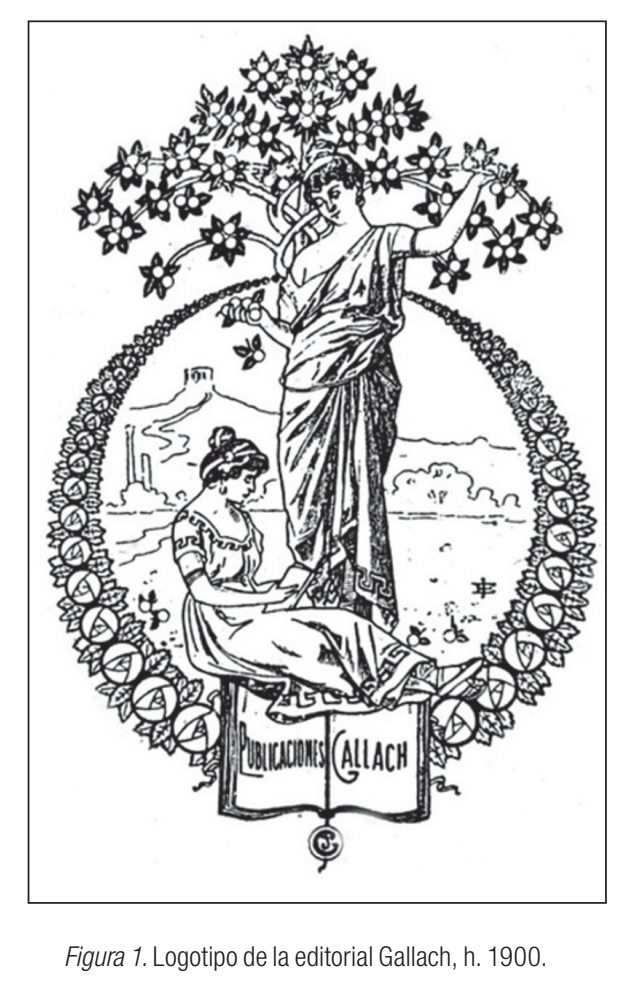


El primer libro con el sello Gallach, documentado en la Biblioteca Nacional de España y en la de Cataluña, fue Literatura militar española del capitán Francisco Barado, fechado en 1890. En la última década del siglo XIX Gallach compró los fondos de la editorial Soler, situada en el número 152 del Pasaje San Juan de Barcelona, y más tarde en Consejo de Ciento 416-418, que imprimía en los talleres Baseda de Domingo Clarasó con sede en Villarroel 17. Esta empresa de Barcelona (denominada entonces Sucesores de Manuel Soler) había alcanzado gran popularidad y en la publicidad indicaba que se inspiraba en el siguiente lema: "La instrucción y educación es la mayor riqueza que pueden alcanzar los pueblos".

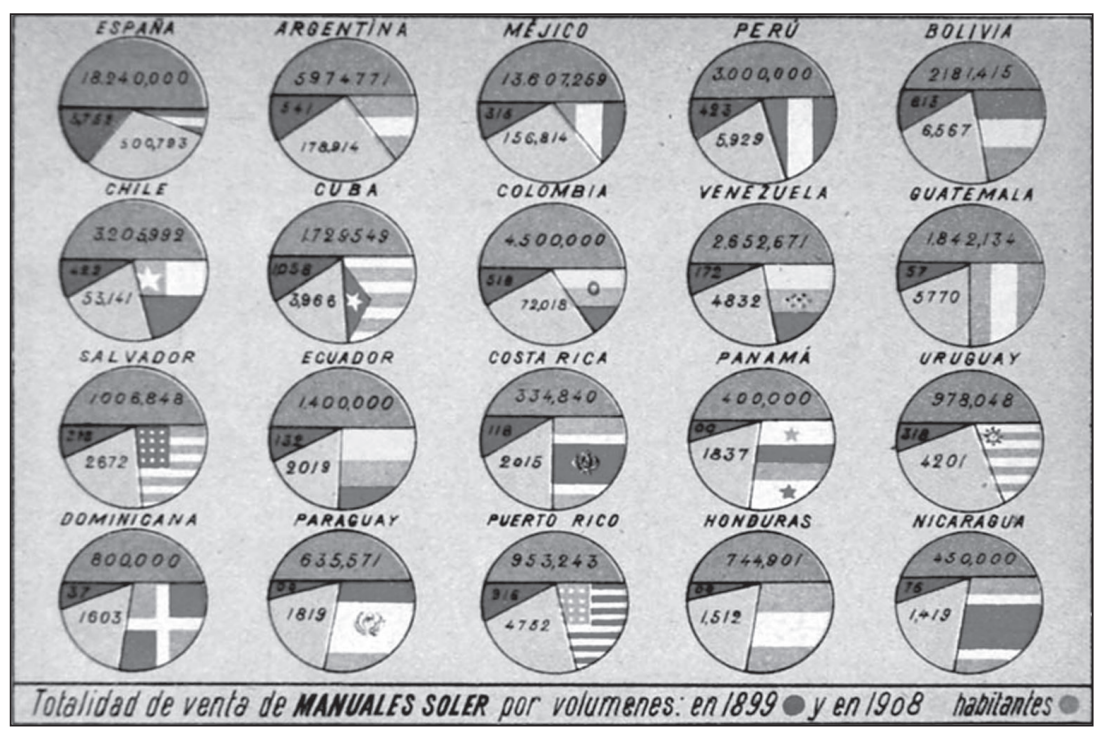

Figura 2. Venta de los Manuales Soler 1899-1908.

Fuente: Manuales Soler. Guardas de los libros.

La colección emblemática de la editorial Soler fueron sus Manuales Soler (Figura 2), caracterizados por su reducido formato $(11 \times 16 \mathrm{~cm})$ y por la encuadernación en cartoné de color naranja estampado en negro, que tras la compra por Gallach cambiaría a verde. Soler editó un centenar de volúmenes en dos series distintas, numeradas en arábigos y romanos, y diseñó un mueble especial para su exposición que regalaba a los suscriptores. Para la difusión del fondo se publicó el periódico Lecturas Populares. Revista mensual de conocimientos útiles y bibliografía, gratuita y distribuida en sociedades, ateneos y centros instructivos. Los Manuales se promocionaron como una "Biblioteca útil y económica de conocimientos enciclopédicos”, señalando como objetivos lo siguientes: 
Contribuir a este movimiento redentor, penetrados de la imperiosa necesidad de popularizar los principios de la ciencia moderna, sus grandes conquistas, las manifestaciones del arte, poniendo todo al nivel del menos culto y ofreciendo a los hombres de mayor elevación intelectual una fórmula sencilla que pueda servirles de recuerdo en cada materia científica; para que nadie tenga que recurrir a libros extranjeros en cuanto a fundamentos de la ciencia. ${ }^{7}$

La editorial Gallach se anunció en los primeros meses como "José Gallach-Editor. Sucesor de Manuel Soler", con oficinas en Consejo de Ciento 416-418 y Pasaje de Tasso 9, más los almacenes en la carretera de Horta. El primer catálogo estuvo compuesto por las obras de referencia procedentes de Soler, de gran interés para profesionales y estudiosos, como los Manuales, la colección La Ciencia del Arte o la Biblioteca Jurídico Popular, y por títulos especializados como Monumentos del Arte Español de Pedro Huguet, en gran formato y con un centenar de fototipias, o Tesoro del agricultor. Novísimo tratado teórico-práctico de Agricultura y Zootecnia.

José Gallach participó en los eventos e instituciones proyectados por los editores en defensa de sus intereses y se afilió al Instituto Catalán de las Artes del Libro desde su fundación en 1898. Estuvo vinculado a los círculos de intelectuales y artistas del modernismo, e incluso fue jurado en el concurso de fotografía convocado con motivo de la Festa dels Coloms que se celebró el 17 de marzo de 1907 en el Tibidabo, junto a Pau Audouard, José Baltá de Cela, Miquel Utrillo y Josep María Co de Triola. ${ }^{8}$ Fue también secretario del Centro de la Propiedad Intelectual creado en 1900, ${ }^{9}$ y en 1909 participó en la Primera Asamblea Nacional de Editores y Libreros celebrada en Barcelona entre los días 7 y 9 de junio, donde pronunció la conferencia "Medios prácticos para fomentar y activar el comercio de libros en España y entre la Península y las naciones americanas de origen español". ${ }^{10}$ Su aportación consistió en analizar el mercado del libro en el continente americano, valorando

7 Tomado del texto de presentación de la colección en el libro de Carlos Banús y Comas, Unidades, Manuales Soler núm. XXI, Barcelona, s. f., p. 4.

8 Nuria Fernández Rius, Pau Audouard, fotògraf retratista de Barcelona De la reputació a l'oblit (1856-1918), p. 413.

9 Los Estatutos del Centro de la Propiedad Intelectual de Barcelona fueron aprobados el 6 de junio de 1900 con 17 artículos. Los objetivos fueron "defender los intereses generales de las industrias representadas en la Asociación y procurar su mejoramiento y desarrollo; constituir ante los poderes públicos una representación legal autorizada para defender y velar por los intereses de los asociados en todo lo concerniente al articulado y reglamento de la Ley de Propiedad Intelectual de 1879 y 1880". El documento original se conserva en el Arxiu Nacional de Catalunya y está firmado por Francisco Simón y Font, fundador de la editorial Montaner y Simón. Arxiu Nacional de Catalunya, ANC1-261-T-123.

10 Véase Philippe Castellano, “América: ¿arcadia para editores españoles?”, en Naveg@mérica. Revista electrónica de la Asociación Española de Americanistas, núm. 5, 2010. Disponible en http://revistas.um.es/navegamérica 
el trabajo de los editores europeos para distribuir sus fondos y proponiendo medidas para la mejora de la actividad. Las propuestas concretas fueron tres: determinar las necesidades, gustos y exigencias de los lectores, mejorar los sistemas de venta y analizar la solvencia de los libreros:

El estado actual del comercio de libros entre España y las naciones americanas de origen español, hemos de confesarlo, carece de la importancia, estabilidad y florecimiento que deberían serle peculiares... La acción de nuestros competidores es mucho más intensa, bastante más práctica y decididamente más enérgica que la nuestra en cuanto al sostenimiento de aquellos mercados se refiere y a los medios que pone en práctica para colocar sus ediciones.

La caprichosa y variada aplicación de precios establecida por los dedicados a la venta de publicaciones en los países extranjeros de habla española, es uno de los más grandes inconvenientes que se oponen al crecimiento de la exportación; pues es evidente que el excesivo coste de aquellas limita necesariamente el número de compradores y perjudica, por lo tanto, el desarrollo de la producción, y consiguientemente el de la venta. Uno de los frecuentes pretextos de que echan mano con tal objeto los libreros es generalmente el de los cambios. ${ }^{11}$

En 1911 Gallach asistió a la Segunda Asamblea de Editores y Libreros, reunida en Valencia, donde volvió a exponer los problemas sobre la expansión de los editores españoles en América, en un nuevo intento de llamar la atención de los profesionales sobre un mercado todavía inexplorado.

Ese mismo año, para la difusión de sus fondos creó Mi Revista (Figura 3), subtitulada Periódico-Ilustración para el Hogar y comercializada mediante suscripciones. Tuvo la redacción y administración en la misma sede que la editorial (Consejo de Ciento, 418), su periodicidad fue quincenal y cambió dos veces de subtítulo: Enciclopedia Ideal para el hogar y la Escuela, y Enciclopedia Popular Ilustrada. Se editó en dos épocas: la primera entre 1911 y 1919, y la segunda a partir de noviembre de ese año, dependiendo de la editorial Calpe tras adquirir ésta el fondo Gallach. En la cabecera llevaba el dibujo de una mujer leyendo, sin firma, de trazo similar a las creaciones del ilustrador Ramón Casas. Constaba de 24 páginas y era venal, al precio de 0,50 pesetas. La publicidad de la contracubierta se dedicaba a productos de higiene, medicinas, bazares, balnearios, máquinas de escribir y registrar, y además a los libros editados por Gallach. 


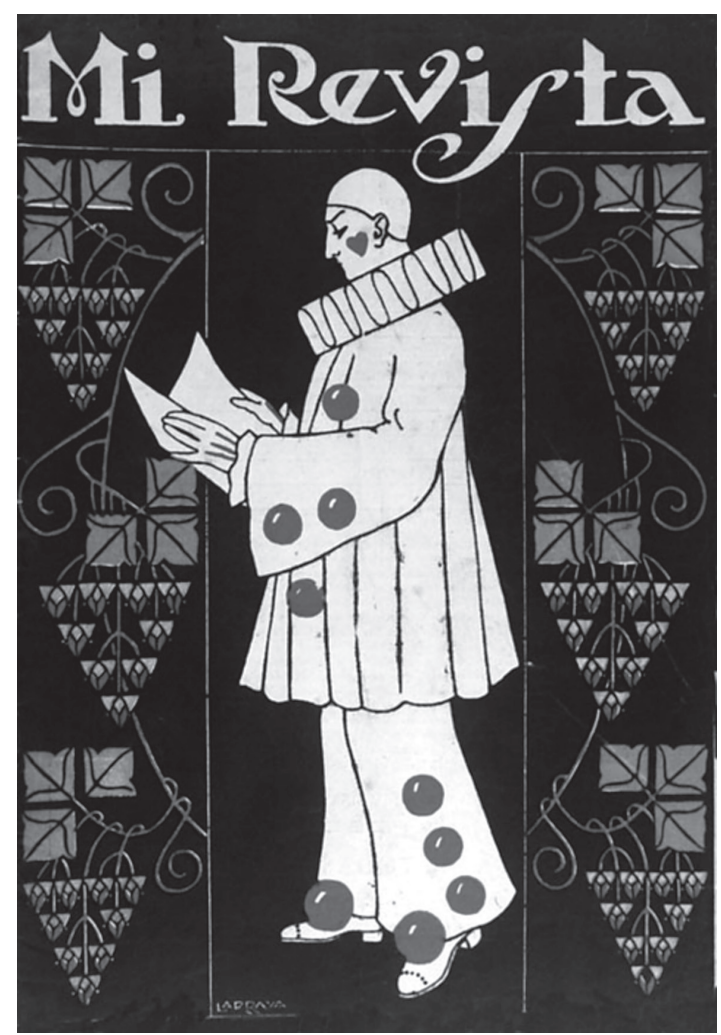

Figura 3. Portada de Mi Revista, 1919.

En cuanto a los contenidos, todas las secciones llevaban una cabecera ilustrada y en ocasiones abundaban los dibujos, en especial en las páginas de moda, con una media de 20 imágenes. Las principales secciones fueron Literatura, Ciencia, Infantil, Historia, Pasatiempos, Casos y Cosas, Labores y Modas, Recetas y Consejos del Doctor. El equipo de redacción estaba formado por Augusto Barrado (secretario), Joaquín María Barnola (Ciencias Naturales), José Comas Solá (Astronomía), Federico Climent Terrer (Economía doméstica), A. O. Viñas (Higiene popular), Salomé Núñez Topete (Moda), Aurora y Tomás Gutiérrez Larraya (Labores femeniles y decorado del hogar) y Arturo Jarque (dibujante).

El número de colaboradores por ejemplar superaba el medio centenar entre escritores e ilustradores, con autores tan prestigiosos como Luis Be1lo, Andrés González Blanco, Enrique González Fiol, Ramón Goy de Silva, Alfredo Opisso, Francisco Rodríguez Marín, Carlos Sarthou, Antonio Velasco Zazo, Antonio Zozaya, Enrique Bráñez, Manuel Bujados, Echea, K-Hito, 
Vicente Ibáñez, Ramón Manchón, Ricardo Marín, José Moya del Pino, José Robledano, José Segrelles y Enrique Varela de Seijas. En 1920, bajo la dirección de Calpe, se incluyó el coleccionable "Teatro Infantil" en formato reducido $(6 \times 9 \mathrm{~cm})$, con obras cortas como Jugar al mañana de Juan Gómez Renovales o Comedia de polichinelas de Jacinto Benavente, ilustradas por Echea. En esta época se anunciaban regalos y ampliaciones fotográficas a tamaño natural para los suscriptores de la editorial.

José Gallach editó también tarjetas postales para anunciar la serie titulada Biblioteca de Episodios Americanos, y la segunda década del siglo XX fue la de expansión, con títulos muy populares de grandes tiradas y encuadernaciones cuidadas, entre ellos la Enciclopedia Moderna Catalana (4 tomos) o la Historia Natural de Odón de Buen (2 tomos), profusamente ilustrada. En 1916 escribió dos curiosos decálogos propagandísticos que reprodujo en Mi Revista, uno de ellos relacionado con la difusión del libro español en los países europeos implicados en la Guerra Mundial, y el otro destinado a los libreros con las excelencias de su editorial. El decálogo sobre el libro español durante la guerra se resumía en el séptimo punto: "No olvides que el libro español es para tu patria y para tu familia, lo que la semilla es en la tierra: el medio de que fructifique y se desarrolle el pensamiento español”. El decálogo para los libreros fue de carácter comercial, plagado de tópicos como el que se cita: "Donde quiera que te dediques a la cultísima y honrosa profesión de librero, no olvides la conveniencia de propagar y vender las Ediciones Gallach".

\section{Creación de la Compañía Anónima de Librería, Publicaciones y Ediciones (Calpe)}

La creación de la prestigiosa editorial Calpe (Compañía Anónima de Librería, Publicaciones y Ediciones) por Nicolás María Urgoiti se llevó a cabo en 1918 con la colaboración de José Gallach, a quien el industrial vasco le compró todo el fondo y le encargó la gerencia de la nueva empresa. El 5 de junio de ese año el Consejo de Administración lo nombró gerente con un sueldo de 30.000 pesetas anuales, más la participación en beneficios, y le concedió poderes para representar a la empresa y para realizar todas las gestiones, en especial los contratos de administración e impresión de revistas, ilustraciones y folletos de carácter cultural, así como los relacionados con la confección y explotación del libro impreso.

Calpe contó por tanto con las propiedades de Gallach: terrenos, instalaciones, maquinaria, y los fondos literarios y artísticos del negocio. A cambio controló la producción, negoció derechos, vendió productos editoriales, gestionó 
los derechos y la publicidad, y controló la administración. La aportación superó el millón de pesetas $(1.047 .200,77)$ abonado en cuatro pagos, el primero en acciones (250.000 pesetas) y el resto en tres cuotas entre julio de 1918 y enero de 1919. Por otra parte, con el fin de trasladar los fondos de la casa Gallach, situados en un almacén de la calle Guinardó, se encargó al arquitecto Francisco Guardia un proyecto para la construcción de una nave en Barcelona, idea que más tarde sería desestimada (Tabla 1).

Tabla 1. Aportaciones de la editorial Gallach a Calpe.12

\begin{tabular}{|l|c|}
\hline \multicolumn{1}{|c|}{ Propiedades } & Valoración \\
\hline Saldo de corresponsales, provisional y pólizas & $152.216,96$ \\
\hline Existencias de obras, materiales y piedras litográficas & $545.823,03$ \\
\hline Importe de máquinas y herramientas & $10.707,00$ \\
\hline Mobiliario & $9.511,50$ \\
\hline Un coche, un caballo y utensilios afines & $2.500,00$ \\
\hline Terrenos en Barcelona y sus calles de Mallorca y Padilla & $300.725,00$ \\
\hline Propiedades literarias y artísticas de obras a publicar & $12.600,00$ \\
\hline Biblioteca particular & $8.000,00$ \\
\hline Importe de los créditos a favor & $5.216,28$ \\
\hline Total Ptas. & $1.047 .200,77$ \\
\hline
\end{tabular}

Calpe hubo de abrirse camino en un momento difícil, puesto que la crisis en el sector del papel era grave y ello había provocado un movimiento general contrario a La Papelera Española, propietaria de la editorial, dirigido por un sector de la prensa y con el apoyo de la Federación Española de Productores, Comerciantes y Amigos del Libro, cuya revista Bibliografía Española publicó el siguiente texto en abril de 1918:

La prensa española y los editores e impresores hemos enriquecido a La Papelera Española, y esta nos paga tal beneficio con la más negra de las ingratitudes; pues a más de crear periódicos para combatir a la prensa, funda una gran casa editorial para acabar de arruinar a los que confeccionamos libros; es decir, que tira a destruir a cuantos la hemos favorecido y la hemos elevado al pináculo de su actual prosperidad. ${ }^{13}$

Cuando los editores supieron que al frente de Calpe se encontraba José Gallach, cambiaron radicalmente de opinión para saludar a la nueva empresa

12 Poder de Nicolás María Urgoiti a José Gallach, Archivo Histórico de Protocolos, 11 de noviembre de 1918. El Consejo de Administración le fijó un sueldo de 30.000 pesetas anuales más los beneficios de participación en la empresa. 
con una cita laudatoria publicada en la misma revista dos meses más tarde: "No nos cabe duda de que han de contribuir a la elevación y engrandecimiento de nuestro comercio y al desarrollo y propaganda de nuestra cultura patria".

Nicolás Urgoiti diseñó una estructura con dos secciones generales: una editorial, con sede en Madrid y controlada por el Comité Directivo con el asesoramiento del director gerente, y otra técnica, comercial y administrativa, con oficinas en Barcelona bajo la dirección de José Gallach, en coordinación con los jefes de cada una de esas áreas: José Nicolás Urgoiti (hijo de Nicolás), Rosendo Gallach y Ricardo Díez Campañá (hijo y yerno de José Gallach, respectivamente). Aspecto fundamental fue la creación de la figura del director literario en la persona de José Ortega y Gasset, tomando ejemplo del editor Victoriano Prieto que había contratado a Gregorio Martínez Sierra para Renacimiento en el año 1911. El Comité Editorial contó además con un secretario, Lorenzo Luzuriaga, encargado también de elaborar las estadísticas sobre publicación y las nuevas producciones.

El Consejo de Administración pidió a José Gallach que preparara un plan de ediciones para la última decena de junio de 1918, y que enviara un ejemplar de cada una de las obras de su fondo con el fin de constituir la biblioteca editorial; es decir, que la base de la gran biblioteca de Calpe fueron los fondos de Gallach. Prácticamente desde la fundación, la idea era establecer depósitos en América, bien propios o en consorcio con otras editoriales. En julio de 1918, Ortega y Gasset fue invitado a impartir conferencias en las Universidades de La Plata y Buenos Aires, y propuso que le acompañara un editor capaz de publicitar los proyectos editoriales y de informarse sobre las obras de texto con los profesores de Argentina, Chile y Uruguay. El Consejo de Administración decidió que acometiera esa tarea el pedagogo Francisco José Barnés Salinas, cuya misión sería elaborar un amplio informe a partir del cual obtener conclusiones definitivas.

En el periodo de rodaje se pusieron a la venta las grandes obras de la Casa Gallach con un intenso programa publicitario entre agosto y diciembre en las revistas del grupo Prensa Gráfica (Nuevo Mundo, Mundo Gráfico y La Esfera). En esta última se reprodujeron anuncios a página de los principales títulos y series: El Abogado Popular de Pedro Huguet (6 tomos encuadernados en tela con 3755 páginas), Agricultura y Zootecnia de Joaquín Ribera (5 tomos ilustrados), Manuales Gallach (106 volúmenes en agosto) y Biblioteca del Electricista Práctico, subtitulada Enciclopedia de Electricidad, dirigida por Ricardo Caro y Anchía (30 volúmenes en formato octavo). Para difundir los fondos de Gallach se abrió la sección de Publicidad, dirigida por José Cruz, que cobraba el $10 \%$ de los ingresos de cada anuncio, y se propuso la 
confección de un periódico quincenal gratuito que formara parte del programa general de propaganda.

La primera idea fue establecer las oficinas y talleres en Barcelona, sin embargo en julio de 1919 Gallach recibió la orden de trasladarse a Madrid y envió una carta a Urgoiti el 18 de ese mes, presentando la editorial como: "Una empresa instituida con el fin de reunir discretamente todo lo que en buen grado de bondad, y sin distancia de doctrina, produce el pensamiento humano".

El documento, extraordinario para entender la función del editor en relación con el autor a principios de siglo, es el testimonio de un empresario que invertía su patrimonio y profesionalidad en un proyecto a medio y largo plazo. Para Gallach, la tarea del editor respondía a los siguientes criterios:"Operar sin presión moral que cohibiese y malograse las concepciones, asesoramiento sin cortapisas ni intromisiones de ninguna clase y utilización libre de los factores o elementos de valor literario o artístico que juzgue más idóneos, tanto de uno como de otro bando doctrinal". ${ }^{14}$

\section{Gallach gerente de Calpe}

La actitud de Gallach como gerente fue crítica desde el comienzo del proyecto, señalando los "defectos y errores" derivados de la duplicidad de funciones realizadas por él como gerente y por José Ortega y Gasset como director editorial. El Consejo de Administración le había concedido plenos poderes a Ortega para seleccionar obras y autores, y ello ataba las manos a Gallach, tanto que pidió a Urgoiti que retomara la idea inicial, advirtiendo de los problemas si el control seguía en manos de un editor y no de un comercial o industrial. Esta dicotomía entre el intelectual y el profesional del libro le hizo escribir lo siguiente en la carta citada:

\footnotetext{
Ya sé la descalificación que merece el editor al literato, y sin duda de esto debió nacer el plan de que el organismo intelectual de Calpe residiese en Madrid, partiendo de que la parte industrial y comercial debe estar supeditada y regularse por lo que dicte la dirección o asesoría literaria. ¡Craso error! Esto no ha ocurrido ni ocurre en ninguna casa editorial, no diré en España, pasando por Calleja, por Sopena y otros muchos, sino del mundo entero. La parte industrial y comercial, fin primordial de toda empresa, debe predominar sobre la literaria sin que esto quiera decir que a esta se la excluya.

Una de las primeras propuestas de Gallach en su función de gerente fue la edición de un periódico gratuito de carácter comercial, que continuara la 
labor de Mi Revista, órgano de difusión de la editorial Gallach hasta su adquisición por Calpe. Esta publicación, que se tituló Revista de Libros, inició una segunda etapa bajo el sello Calpe a partir de noviembre de 1919 con el objetivo de captar nuevos clientes.

En los tres primeros años de funcionamiento, Calpe compuso un catálogo de calidad con varias colecciones de relevancia: Universal, Viajes Clásicos y Contemporáneos y Grandes Obras. La necesidad de aumentar las ventas para conseguir beneficios llevó al equipo directivo a negociar con la familia Espasa la exclusiva de venta de la Enciclopedia Universal Ilustrada, y a la apertura de una delegación en Buenos Aires (Suipacha, 585) con Julián Urgoiti a la cabeza. Esta decisión fue un revulsivo para la industria papelera y editorial española, que contó a partir de entonces con una gran empresa para la distribución de fondos en un mercado dominado por los editores franceses (Franco-Americana, Garnier, Armand Collin, Hachette, Michaud, etcétera).

En 1922, tras tres años como gestor, el trabajo de Gallach fue cuestionado. Serapio Huici, directivo de La Papelera Española, accionista mayoritaria de Calpe, pretendió bajarle el sueldo y se sintió ofendido. El 17 de julio el conde de Aresti, presidente de La Papelera, le pidió a Urgoiti que resolviera la situación y buscara una salida airosa en atención a los servicios prestados. ${ }^{15}$ Gallach puso el cargo a disposición de Urgoiti y solicitó su traslado a la recién creada delegación en Barcelona para llevar los asuntos comerciales. Urgoiti le pidió que elaborara un informe con su visión personal de la situación y el análisis de la marcha de Calpe. ${ }^{16}$ El gerente supo desde el primer momento que redactaba una especie de "testamento profesional" con el que ponía punto y final a su actividad al frente de la editorial. Fue contundente en su juicio y analizó los aspectos intelectual, industrial y comercial, insistiendo de nuevo, como había hecho en 1919, en la necesidad de un cambio en la política editorial, basándose en los siguientes aspectos: modificación de las secciones literarias con incentivos económicos según la producción, eliminación de los editores del Comité Directivo, independencia de los talleres, publicación de grandes obras y de contenido general, creación de la sección de propaganda y reivindicación del papel del editor.

El editor es el tirano, porque investiga, busca el libro que le reclama el mercado; vigila lo que hace el competidor; se esfuerza en producir en condiciones económicas favorables, porque si así no lo hace ve con horror las cifras de las nóminas; se da cuenta de cómo se van llenando de libros los estantes y anaquelerías, se percata del valor negativo que se acumula enfrente del positivo que le reclama el accionista

15 Archivo Regional de la Comunidad de Madrid (ARCM), Archivo Urgoiti C 35. 2/97.

16 Informe Gallach realizado a petición de Urgoiti. ARCM, Archivo Urgoiti C 53.3/11. 
y teme que pueda llegar el caso de que se le atribuya el desastre en primer término, antes que al Comité Directivo y al Consejo de Administración.

La misión de los directores de colección, según Gallach, era proponer títulos y revisar originales y traducciones con absoluta responsabilidad, normas que ninguno cumplía por falta de intensidad de trabajo y actitud crítica. Por otra parte, consideraba imprescindible combinar la edición de obras prácticas con libros de gran formato, basándose en la idea de que la inversión en recursos humanos e infraestructura era la misma para ambos modelos. En cuanto a la publicidad, diseñó la sección modelo basada en cinco apartados: Técnico (planificación, redacción de documentos y publicidad en prensa), Propaganda directa (clientes), Propaganda a intermediarios (libreros, corresponsales, viajantes, etc.), Registro de resultados (estadísticas e informes) y Cooperación de Amigos del Libro (suscripciones). Su funcionamiento seguía las siguientes pautas: información general sobre el libro (precio, importancia de la edición, serie, etc.), plan ideal de propaganda, medios más apropiados para la máxima rentabilidad, redacción de documentos, estudio de la prensa más apropiada, dossier de prensa, control de correspondencia, registro y estadística de resultados. Para el aumento de producción propuso la creación de una nueva sociedad encargada de realizar los trabajos ajenos a la empresa y, por último, criticaba la política de ventas y apuntaba la idea de crear un departamento de propaganda que publicitase las obras, así como el puesto de un inspector general que supervisase la marcha de la empresa en todos sus cometidos. Estas observaciones no fueron un simple análisis de la situación sino un código para corregir la línea editorial y la retirada del "frente de batalla". Al tiempo que proponía su relevo, alegando motivos de salud, explicaba las tareas del gerente editorial, insistiendo en el papel negativo de los intelectuales como editores.

El demoledor informe de Gallach tuvo respuesta puntual. Nicolás Urgoiti no aceptó las críticas a los intelectuales, dirigidas fundamentalmente a Ortega y Gasset, con quien el gerente había discrepado desde la fundación de la editorial por entender que usurpaba parte de sus funciones. En consecuencia, el director de Calpe censuró su intromisión en los aspectos editoriales y le pidió que continuara colaborando pero sólo en aspectos técnicos. ${ }^{17}$

\section{Gallach director de la Delegación de Barcelona}

El 27 de abril de 1922 se anunció la expansión de Calpe hacia América y la

17 Observaciones sugeridas por la lectura del informe que a mis instancias ha presentado el señor Gallach, director gerente de Calpe (sin fecha). ARCM, Archivo Urgoiti, C 53.3/12. 
creación de una delegación de la editorial en Barcelona con Gallach al frente. Su actividad, en principio con plena autonomía, consistió en comercializar los libros en Cataluña, Valencia, Aragón y Baleares. Con él trabajaron su hijo Rosendo y su yerno Ricardo Díez Campañá. Sin embargo la empresa no obtuvo los resultados esperados y en 1923 presentó pérdidas, debido sobre todo a las cargas por el alquiler de los locales que ocupaban. El Consejo de Administración de Calpe propuso el cierre de la sucursal, aunque finalmente se mantuvo abierta. Urgoiti viajó a Barcelona en enero de 1924 para pedir a Gallach mayor economía en los gastos. En carta enviada el 19 de febrero al Comité Directivo, Gallach propuso cambios en el contrato de explotación para conseguir mayor rentabilidad: autorización para dedicarse a la edición y apertura de una librería, mantener los mismos corresponsales de venta en Barcelona, cesión gratuita de una parte de los locales para atender cuestiones personales y renuncia al sueldo fijo anual de 20000 pesetas en compensación a las peticiones (Figura 4).

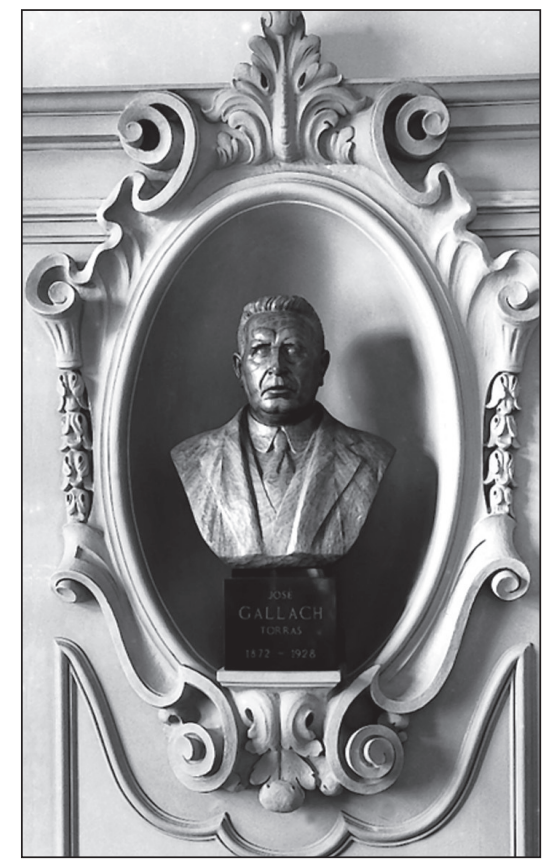

Figura 4. Escultura de José Gallach en el Instituto Gallach de Barcelona, h. 1924. Instituto Amatller (Archivo Mas).

Estos planteamientos aumentaron las discrepancias y los consejeros presionaron a Urgoiti para que tomara medidas drásticas. La desconfianza llegó 
al extremo de establecer controles sobre el patrimonio de la empresa. A partir de febrero de 1924 el intercambio de cartas fue constante y las órdenes desde Madrid tajantes: Gallach debía actuar como comisionista y abandonar dos de los tres locales de la editorial. Aún así ignoró las decisiones y Urgoiti tuvo que viajar de nuevo en el mes de marzo, acordando por fin que los gastos de la Delegación se descontaran de los ingresos por ventas. El problema de fondo no quedó resuelto porque las ventas descendieron todavía más. Urgoiti se vio obligado a organizar otros dos viajes en mayo y octubre de 1924 para gestionar personalmente los cambios. La delegación era un problema añadido al conjunto de la situación de Calpe y sólo cabía el cierre como solución.

\section{Creación y desarrollo del Instituto Gallach}

A finales de 1924 José Gallach salió definitivamente de Calpe y decidió continuar con la actividad editorial. Creó entonces el Instituto Gallach de Librería y Ediciones, dedicado a la publicación de grandes obras ilustradas sobre historia, arte, geografía e historia natural. Sus colaboradores directos fueron su hijo Rosendo Gallach y su yerno Ricardo Díez Campañá, con quienes participó activamente en la Cámara Oficial del Libro, donde Rosendo ocupó el cargo de vocal del consejo directivo. Cuatro años después, en 1928, ya habían editado varios títulos de gran difusión, entre ellos Historia Natural (4 tomos), Razas Humanas (2 tomos) y Geografía Universal (4 tomos), colecciones por las que la editorial fue premiada con Medalla de Oro en la Exposición Universal de Barcelona de 1929.

José Gallach Torras falleció el 14 de noviembre de 1928, pero el negocio continuó en manos de su hijo y de su yerno. La noticia de su muerte apareció en una breve nota de La Vanguardia el 30 de ese mes, con una apostilla que lo destacaba por las relaciones familiares y no por su prestigio como editor: "emparentado con la distinguida familia Campañá de esta localidad".

La actividad del Instituto Gallach continuó después de la guerra civil con la edición de obras profusamente ilustradas y en gran formato que fueron publicándose durante los años cuarenta. La mayoría de ellos alcanzaron gran popularidad: Historia de España, Gran Historia General de los Pueblos Hispanos, Mil Figuras de la Historia o Mil Lecciones de la Historia. Estas obras contaban con varios tomos y se comercializaban mediante venta a plazos y por suscripción.

Gallach fue comprada en 1979 por la editorial Océano, empresa que no dejó de utilizar el sello para la comercialización del fondo. En el catálogo impreso de 2004 figuraban todavía las siguientes obras: Historia Universal, 
Historia del Arte, Historia Natural y Razas Humanas, y en el catálogo en línea de 2012 se ofertaban los apéndices de la Enciclopedia Universal Gallach de 2005 y 2008 , con el siguiente texto:

Complemento imprescindible para mantener actualizada la más amplia biblioteca universal. Los dos volúmenes, con 400 páginas y un Cd-Rom, incluyen las biografías actualizadas de los más importantes personajes de la actualidad política, científica, literaria y artística, así como el obituario de las personalidades desaparecidas entre 2005 y 2007. Cuenta también con la sección Las Mejores Fotos, con las imágenes más espectaculares de los últimos años.

\section{El catálogo del Instituto}

Las obras de la editorial Gallach se caracterizaron por su contenido especializado, la profusión de ilustraciones y la evidente intención divulgativa. El primer libro del que se tiene referencia, con dos ejemplares conservados en la Bibliotecas Nacionales de Madrid y Cataluña, es Literatura militar española, del capitán Francisco Barado (post scriptum de Luis Vidart), editado en Barcelona con el pie "Casa Editorial Gallach" en el año 1890 (740 pp., 16 lám.). No hay constancia en los fondos investigados de más libros fechados entre ese año y 1900, por lo que suponemos que en aquella década fue adquirido el fondo de Manuel Soler y se comenzaron a editar las obras de gran formato, entre ellas El Abogado Popular de Pedro Huguet (6 tomos), Agricultura y Zootecnia de Joaquín Ribera (5 tomos), La vida de los animales de A. E. Brehm (6 tomos), y Museo Militar, también de Francisco Barado. La vida de los animales, traducida por Carlos Fernández Castroverde, se dividió en seis partes: Mamiferos (I y II), Aves (III y IV), Reptiles, Anfibios y Peces (V) e Invertebrados (VI), con profusión de ilustraciones (1650 en blanco y negro más litografías en color), y se vendió en fascículos encuadernables en piel editorial. Museo Militar fue considerado el libro más importante sobre milicia, y en la Exposición Universal de Barcelona de 1888 obtuvo una Medalla de Oro. Calpe estructuraría después el contenido de esta obra en tres tomos, en el año 1923.

En el catálogo de 1916 se ofertaban, entre otros títulos, los siguientes: Diccionario de las Familias (Enciclopedia del Hogar en fascículos), Contabilidad General y Contabilidad Comercial de J. Prats Aymerich, La Ciencia del Arte de Víctor Masriera (5 volúmenes), La letra de cambio de Pedro Huguet, Cuerpo de Derecho Civil Romano de Kriegel, Hermann y Osenbruggen, La Cristiada de Fray Diego de Hojeda y La Divina Comedia de Dante. También se reeditaron ensayos de relevancia del fondo Soler, como El problema de la ignorancia del derecho y sus relaciones con el status individual, el referéndum 
y la costumbre, de Joaquín Costa (1913). De esta obra se conserva un ejemplar en la Biblioteca del Ateneo de Barcelona. Entre las colecciones fueron de relevancia la Biblioteca de Episodios Americanos y la popular Biblioteca del Electricista Práctico, denominada también Enciclopedia de Electricidad, que dirigió Ricardo Caro y Anchía, sobre la que leemos en el catálogo de Calpe de 1923:

La más moderna, más concisa, más clara, más completa, más económica, más manuable y más primorosamente ilustrada de cuantas se han publicado hasta hoy. Obras sumamente prácticas y originales, redactadas por autores especialistas, bajo la dirección de Ricardo Caro y Anchía, licenciado en Ciencias Fisico-Matemáticas, oficial de Telégrafos y profesor de Electrotecnia y Telegrafía en la Escuela Industrial de Tarrasa.

En cuanto a las series y obras de formato menor, destacaron Literatura militar española de Francisco Barado, Lecciones de árabe marroquí de Pelayo Vizuete, Prontuario de esperanto e Índice legislativo español, ambas de José Garzón Ruiz, Diccionario de voces cubanas de Constantino Suárez, Derecho consuetudinario y economía popular en España (autores varios), Historia de España y de las Repúblicas Hispanoamericanas de Alfredo Opisso y Viñas (25 tomos ilustrados con mapas y láminas), Guía ilustrada de las carreras y de la enseñanza en España (autores varios), Biblioteca Gallach de Novelas, Biblioteca de Episodios Americanos, y la emblemática colección Manuales Gallach que sería explotada por Espasa-Calpe hasta los años cincuenta y que en 1916 sumaba 100 títulos. Una de las obras de mayor éxito fue la Enciclopedia Moderna Catalana de Josep Fiter, editada en 1913 y compuesta por cinco volúmenes con más de diez mil entradas biográficas, geográficas e históricas para la que Gallach escribió el prólogo titulado Quatre paraules del editor.

\section{Manuales Gallach}

La colección tuvo su origen en los Manuales Soler procedentes de la editorial Manuel Soler, a la que Gallach, como ya hemos apuntado, compró el fondo (Figura 5). Estos libros fueron muy populares en el primer tercio del siglo por su variado contenido (ciencia, historia, técnica, artes y oficios, etc.), su formato en octavo y su encuadernación en tela verde estampada en negro. Los dos primeros números, probablemente impresos en 1903, fueron Química General del doctor Luanco e Historia Natural de Odón de Buen, y en mayo de 1914 Jacinto Octavio Picón dedicó a la colección estas palabras en Mi Revista: "Considero de grandiosísima utilidad los Manuales Soler, que por la inteligencia con que están dirigidos me parecen poderoso elemento de cultura, y 
en una palabra que forman una publicación que ha de ser mirada con profunda simpatía por cuantos amen a España".

En 1916 se publicó el número 100 (Manual del pintor decorador por José Cuchy) y para la venta a plazos del conjunto se diseñó un mueble modernista. En agosto de 1918, momento en que Calpe comenzó su actividad, salió el número 106, y a partir de entonces la media anual fue de 5 títulos. Su demanda fue constante y durante meses, hasta que se crearon las nuevas colecciones, fue uno de los pilares económicos de la editorial. Las tiradas medias oscilaron entre los 3000 y 4000 ejemplares, con constantes reimpresiones. Después de la fusión entre Calpe y Espasa en el año 1925 se decidió limitar la colección a 130 títulos, sustituyendo los de escasa venta por otros nuevos con el mismo número, lo que ocasionó confusión entre los clientes.

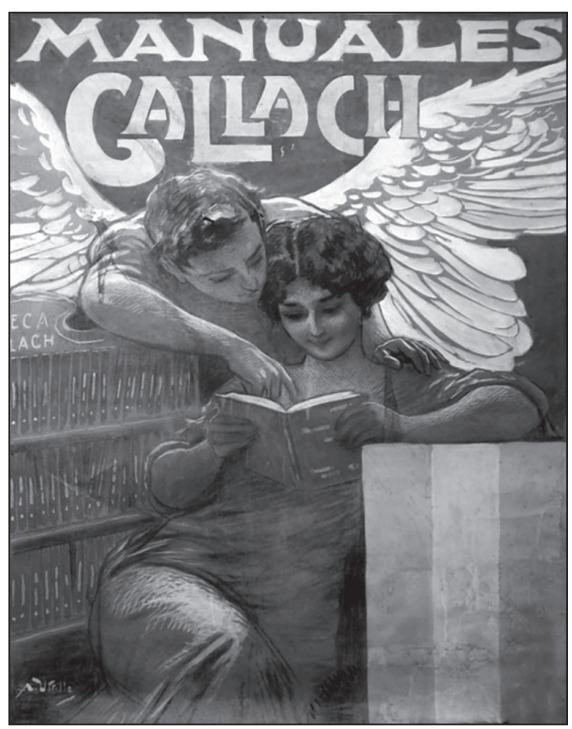

Figura 5. Cartel de los Manuales Gallach.

Original de Antonio Utrillo.

\section{Catálogos generales y especializados: el documentario gráfico}

La producción de Gallach a través del Instituto creado en 1924 fue extraordinaria en cantidad y calidad, presentada en los catálogos generales y especializados que se publicaron hacia 1930 (Figura 6). Eran exquisitos en cuanto a su presentación, con formato 11.5 x $14 \mathrm{~cm}, 16$ páginas profusamente ilustradas e impresas en huecograbado, y con cubiertas litográficas en color diseñadas por Tusell. El trabajo del Instituto en los primeros cinco años de su 
existencia había sido premiado con Medalla de Oro en la Exposición Internacional celebrada en Barcelona en 1929. Por entonces se habían editado tres grandes obras: Razas Humanas (2 tomos, 1924), Historia Natural (4 tomos, 1925) y Geografía Universal (5 tomos, 1928), y se encontraba en proyecto Historia Universal (6 tomos, 1931). Estas cuatro obras compusieron el catálogo general titulado Producciones Selectas, creado para presentar la serie.

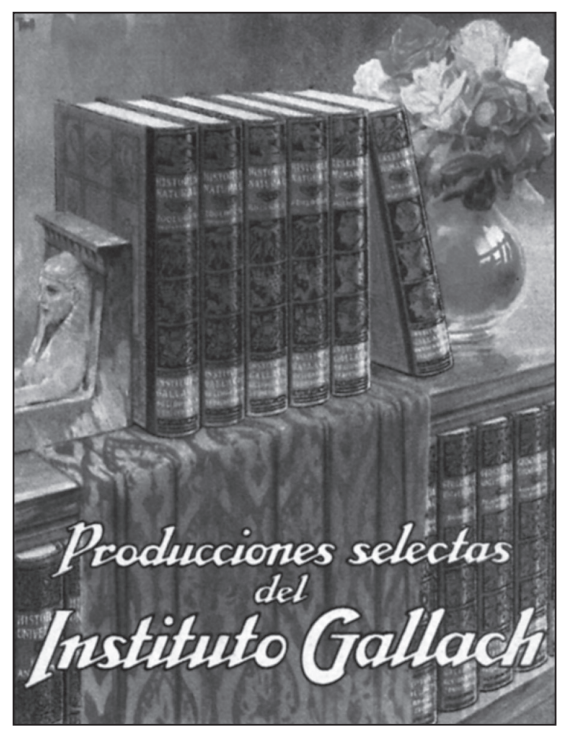

Figura 6. Catálogo de las Producciones Selectas del Instituto Gallach, h. 1930.

Las características fundamentales de estas obras fueron el formato mayor que folio, su elegante encuadernación editorial con las tapas estampadas en oro y la gran cantidad de ilustraciones. Entre las cuatro citadas sumaron 17 volúmenes, 9060 páginas, 18500 grabados directos en blanco y negro, y 1 480 láminas impresas en huecograbado con tono sepia.

En algunos de los catálogos diseñados para la promoción de cada título se incluyeron textos de presentación en los que se empleó el término "producción documental" para referirse a la ingente cantidad de ilustración (catálogo de Historia de España, 1942), y de manera más específica el de "documentario gráfico", archivo o fondo documental de imágenes creado como base para ilustrar cada obra. Este banco de imágenes de la editorial fue origen de los dos tomos titulados Mil figuras de la historia, de cuyo texto se encargó el catedrático Jaime Vicens Vives. A la conformación del corpus y al uso de los originales se hace referencia en el catálogo de 1944: 
El archivo se nutrió con el resultado de búsquedas constantes, llevadas con frecuencia a extremos de verdadero afán de captura. Pronto, entre otros temas, destacó la importancia de la iconografía humana. Los retratos se reunieron a millares... y así nació la idea, ante el polifacético valor de lo reunido, de lanzarse a la magna realización de la nueva obra.

La producción de obras ilustradas generó gran cantidad de material gráfico y en consecuencia un importante archivo compuesto por originales procedentes de diversas instituciones y fototecas públicas y privadas. No se dispone de información sobre dicho fondo y debemos presuponer que pasó a la editorial Océano cuando esta empresa compró Gallach en la década de los años setenta del siglo pasado.

\section{Publicaciones de Gallach en la Biblioteca Nacional de España, Biblioteca Nacional de Catalunya y Ateneos de Madrid y Barcelona}

Con el objeto de recuperar el catálogo de la editorial Gallach se llevó a cabo una investigación en cuatro bibliotecas, dos de ellas de especial relevancia: la Nacional de España y la Nacional de Cataluña, donde se encuentra el mayor número de obras dadas las características y funciones de estas instituciones y por ser Barcelona el lugar de edición de Gallach. Se añaden además las bibliotecas de los Ateneos de Madrid y Barcelona, por ser ambos centros representantes de la cultura en el periodo de mayor actividad de la editorial. Se han localizado 236 títulos, de los que el $44.45 \%$ son de la colección Manuales Gallach (Tabla 2). Los ejemplares se reparten casi por igual en la Biblioteca Nacional de España (105) y en la de Cataluña (114), mientras que en los Ateneos tan sólo se conservan 24 títulos (16 en Madrid y 8 en Barcelona).

Tabla 2. Fondo Gallach en las bibliotecas consultadas.

\begin{tabular}{|l|l|l|l|l|l|}
\hline \multicolumn{1}{|c|}{ Sello Editorial } & \multicolumn{1}{|c|}{ Gallach } & José Gallach & \multicolumn{1}{|c|}{$\begin{array}{c}\text { Instituto } \\
\text { Gallach }\end{array}$} & $\begin{array}{c}\text { Manuales } \\
\text { Gallach }\end{array}$ & \multicolumn{1}{|c|}{ Total } \\
\hline Nacional de España & 21 & 7 & 30 & 47 & 105 \\
\hline Nacional de Cataluña & 14 & 15 & 31 & 54 & 114 \\
\hline Ateneo de Madrid & - & - & 11 & 5 & 16 \\
\hline Ateneo de Barcelona & - & 1 & 5 & 2 & 8 \\
\hline Totales & 35 & 23 & 77 & 108 & 243 \\
\hline
\end{tabular}

De estos ejemplares se repiten 64, por lo que finalmente resultan 179 títulos. En las bibliotecas nacionales se repiten 43; del Ateneo de Madrid con 
respeto a las bibliotecas nacionales se repiten 13 de 16, y del Ateneo de Barcelona 7 sobre 8 . En determinados casos, aunque el título es el mismo la edición es diferente: Las razas humanas, con edición de 1928 (BNC) y de 1958 (BNE) o Mil figuras de la historia, edición de 1944 (BNC) y de 1958 (BNE). Se constata también que cambian los títulos en algunos números de la colección Manuales Gallach. Son ejemplo Artificios de fuegos de guerra (BNE) y El gramófono moderno (BNC) con el número 32, Los centros de contratación (AB) y Operaciones de bolsa (BNE), con el 48, Iniciación del empleado de Banca (BNE) y Los remedios vegetales con el 69, o Estudios de estética (BNC) y Manual del cajista de imprenta (BNE) con el 104. Se indican a continuación los títulos, autores y fechas de edición en las bibliotecas de los cuatro centros.

\section{Libros Gallach en la Biblioteca Nacional de España}

El catálogo de la Biblioteca Nacional de España cuenta con 105 títulos de la editorial Gallach, que aparecen referenciados de cuatro formas diferentes (Tablas 3-6): a) Gallach (21 títulos), b) José Gallach (7 títulos), c) Instituto Gallach (30 títulos) y d) Manuales Gallach (47).

a) Gallach

Tabla 3. Libros con el sello Gallach en la Biblioteca Nacional de España.

\begin{tabular}{|l|c|c|}
\hline \multicolumn{1}{|c|}{ Título } & Autor & Fecha \\
\hline Acumuladores & Francisco Villaverde & $1910-1920$ \\
\hline Alternadores & Francisco Villaverde & $1910-1920$ \\
\hline Averías en las máquinas eléctricas & Francisco Alsina y Alsina & $1910-1920$ \\
\hline Corrientes alternas & Ricardo Caro y Anchía & $1910-1920$ \\
\hline Devanados de generadores y motores eléctricos & Ricardo Caro y Anchía & $1910-1920$ \\
\hline Diccionario de las familias & - & 1925 \\
\hline Electricidad y magnetismo & Ricardo Caro y Anchía & $1910-1920$ \\
\hline$H^{\circ}$ de España y de las Repúblicas Latino-Americanas & Alfredo Opios & 1925 \\
\hline Líneas eléctricas & Ricardo Caro y Anchía & $1910-1920$ \\
\hline Literatura militar española & Francisco Barado & 1890 \\
\hline Manual de flores artificiales & Dolores Andreu & $1911-1916$ \\
\hline Máquinas dinamoeléctricas & Francisco Villaverde & $1910-1920$ \\
\hline Motores de corriente alternativa & Francisco Villaverde & $1910-1920$ \\
\hline Motores de corriente continua & Francisco Villaverde & $1910-1920$ \\
\hline Nuevo formulario de perfume y cosmética & Manuel Dronda y Surio & - \\
\hline Pararrayos y limitadores & Ricardo Caro y Anchía & $1910-1920$ \\
\hline Pilas eléctricas & Francisco Villaverde & $1910-1920$ \\
\hline Reostatos industriales & Ricardo Caro y Anchía & $1910-1920$ \\
\hline
\end{tabular}


LA EDITORIAL GALLACHY SU CONTRIBUCIÓN A LA INDUSTRIA CULTURAL ESPAÑOLA...

\begin{tabular}{|l|c|c|}
\hline Tradición del ganadero, La (1815-1818) & Guillermo Núñez de Prado & $192 ?$ \\
\hline Transformadores y convertidores & Francisco Villaverde & $1910-1920$ \\
\hline Un idilio en el Cauda (1810-1814) & Guillermo Núñez de Prado & $192 ?$ \\
\hline
\end{tabular}

\section{b) José Gallach}

Tabla 4. Libros con el sello José Gallach en la Biblioteca Nacional de España.

\begin{tabular}{|l|c|c|}
\hline \multicolumn{1}{|c|}{ Título } & Autor & Fecha \\
\hline Artificios de fuego de guerra & José de Lossada y Canterac & $1911-1925$ \\
\hline Dibujo para todos ,EI & Víctor Masriera Vila & (s. f.) \\
\hline Guinea española, La & Ricardo Beltrán y Rózpide & $1918-1925$ \\
\hline Historia de la II Guerra Mundial y del III Reich & William Shirer & 1987 \\
\hline Historiadores de Indias & Germán Arciniegas & 1986 \\
\hline Nociones de Higiene industrial & José de Eleizegui & (s. f.) \\
\hline Valor social de leyes y autoridades & Pedro Dorado Montero & $1911-1923$ \\
\hline
\end{tabular}

\section{c) Instituto Gallach}

Tabla 5. Libros del Instituto Gallach en la Biblioteca Nacional de España.

\begin{tabular}{|c|c|c|}
\hline Título & Autor & Fecha \\
\hline Antiguo Egipto, El & Jacques Pirenne & 2007 \\
\hline Apéndice Gallach & Carlos Gisbert & 1993 \\
\hline Apéndice Gallach: 1993-1995 & - & 1996 \\
\hline Apéndice Gallach: 1996-1998 & - & 1999 \\
\hline Apéndice Gallach: 1999-2001 & - & 2002 \\
\hline Apéndice Gallach: 2002-2004 & - & 2005 \\
\hline Apéndice Gallach: 2005-2007 & - & 2008 \\
\hline Cartas de relación & Hernán Cortés & 1986 \\
\hline $\begin{array}{l}\text { Geografía de España: naturaleza, población. vida } \\
\text { económica }\end{array}$ & - & 1930 \\
\hline Geografía de España & Josep Prat Prats & 1994 \\
\hline $\begin{array}{l}\text { Geografía de España: presencia y potencia del suelo y del } \\
\text { pueblo español }\end{array}$ & Ramón Otero Pedrayo & $1955-1956$ \\
\hline Geografía Universal & Carles Carreras i Verdaguer & 1997 \\
\hline Geografía Universal: descripción moderna del mundo & Ferran Valls i Taberner & 1930 \\
\hline $\begin{array}{l}\text { Historia de España: gran historia general de los pueblos } \\
\text { hispanos }\end{array}$ & Luis Pericot & 1978 \\
\hline Historia de España & Carlos Gisbert & 1983-1987 \\
\hline Historia de España & Josep Prat Prats & 1993 \\
\hline $\begin{array}{l}\text { Historia Natural: vida de los animales, de las plantas y de } \\
\text { la tierra }\end{array}$ & Ángel Cabrera & $1926-1927$ \\
\hline Historia Natural & Ángel Cabrera & 1989 \\
\hline
\end{tabular}




\begin{tabular}{|l|c|c|}
\hline Historia Universal: Las grandes corrientes de la historia & Jacques Pirenne & 1978 \\
\hline Historia Universal (1931-1932) & Carlos Gisbert & 1998 \\
\hline Historia Universal: novísimo estudio de la humanidad & Pedro Bosch Gimpera & $1932-1937$ \\
\hline Mil aspectos de la tierra y del espacio & Amando Melón y Ruiz de & 1949 \\
\hline $\begin{array}{l}\text { Mil figuras de la historia: nombres ilustres, vidas famo- } \\
\text { sas... semblanzas biográficas }\end{array}$ & Jaime Vicens Vives & 1944 y 1958 \\
\hline Mil joyas del arte español & María Elena Gómez-Moreno & 1947 \\
\hline Mil lecciones de la historia & Jaime Vicens Vives, & 1951 \\
\hline Mil obras maestras del Arte universal & Alexandre Cirici & 1946 \\
\hline $\begin{array}{l}\text { Mundo de los animales, El: la vida en los grandes } \\
\text { ecosistemas }\end{array}$ & & 1985 \\
\hline Razas humanas & Pedro Bosch Gimpera & $1932-1937$ \\
\hline Nuevo Tesoro de la Juventud & & 1977 \\
\hline Vida maravillosa de los animales, La. Vertebrados & Antoni Jonch Cuspinera & 1961 \\
\hline
\end{tabular}

\section{d) Manuales Gallach (Figura 7)}

Tabla 6. Libros de Manuales Gallach en la Biblioteca Nacional de España.

\begin{tabular}{|l|c|c|}
\hline \multicolumn{1}{|c|}{ Título } & Autor & Fecha \\
\hline Electrificación del hogar doméstico, La & Francisco F. Sintes Olives & 1934 \\
\hline Fabricación de jabones y lejías & Juan Vidal y Martí & 1935 \\
\hline Manual de cerámica & Juan Vidal y Martí & 1934 \\
\hline Motores industriales de combustión interna & José S. Company & 1930 \\
\hline Nociones de piscicultura de agua dulce & Severino Corrales Puyol & 1936 \\
\hline 1. Compendio de química general & José Ramón de Luanco & 1926 \\
\hline 11. Hongos comestibles y venenosos & Blas Lázaro e lbiza & 1911,1925 \\
\hline 17. La Guinea española & Ricardo Beltrán y Rózpide & 1904 \\
\hline 25. Gusanos parásitos en el hombre & Marcelo Ribas Mateos & 1918,1925 \\
\hline 29. Historia de la civilización española & Rafael Altamira & 1932 \\
\hline 32. Artificios de fuego de guerra & - & 1911,1925 \\
\hline 33. Agronomía & Aurelio López Vidaur & S. f. \\
\hline 36. Las provincias de España & M. Hernández Villaescusa & 1923 \\
\hline 37. Formulario industrial y doméstico & Porfirio Trias y Planes & 1929 \\
\hline 38. Valor social de leyes y autoridades & Pedro Dorado Montero & 1911 \\
\hline 40. Arte de estudiar & Mariano Rubió y Bellvé & 1911,1925 \\
\hline 45. Contabilidad comercial & José Prats y Aymerich & 1941 \\
\hline 46. Sociología contemporánea & Adolfo Posada & 1911,1925 \\
\hline 48. Operaciones de bolsa & Marcos Jesús Beltrán & 1931 \\
\hline 54. Nociones de carpintería práctica & C. Ferrer y Fábregas & 1934 \\
\hline 57. Manual de entomología & Antonio Benítez Morera & 1936 \\
\hline 59. Gallinero práctico & Carlos de Torres & 1915 \\
\hline
\end{tabular}


LA EDITORIAL GALLACHY SU CONTRIBUCIÓN A LA INDUSTRIA CULTURAL ESPAÑOLA...

\begin{tabular}{|l|c|c|}
\hline 69. Iniciación del empleado de banca & Octavio del Riego Estévez & 1934 \\
\hline 70-71. Las repúblicas Hispano-Americanas & Emilio Hdez. del Villar & 1921 \\
\hline 73. Plantas industriales & Alfredo Opios & 1918,1925 \\
\hline 75. Manual del curtidor y peletería & C. B. Escuder & 1935 \\
\hline 79. Geografía general & Emilio Hdez. del Villar & 1928 \\
\hline 81-82. Elementos de cálculo mercantil & Luis Fuente y Lozanees & 1930 \\
\hline 85. Documentos mercantiles de uso corriente & - & 1918,1925 \\
\hline 88. La pirotecnia moderna & Juan Bautista Ferré Vallvé & 1918,1925 \\
\hline 93. Historia de la arquitectura cristiana & V. Lampérez Romea & 1930 \\
\hline 94. Derecho internacional & Aniceto Sela, & 1932 \\
\hline 98. La abeja y sus productos & Vicente Va y Ripa & 1930 \\
\hline 100. Manual del pintor decorador & José Cuchy & 1934 \\
\hline 101. El dibujo para todos (Cl) & Víctor Masriera Vila & 1921 \\
\hline 102. América sajona & Emilio H. del Villar & 1911,1925 \\
\hline 103. Agrimensura & José Ferré Vergés & s. f. \\
\hline 104. Manual del cajista de imprenta & F. Fábregues & 1933 \\
\hline 106. Manual de flores artificiales & Dolores Andreu & 1911,1916 \\
\hline 107. Formulario práctico de artes y oficios & Federico Climent Terrer & 1927 \\
\hline 115. Abc de la música & Eliseo Carbó & 1950 \\
\hline 117. Historia del arte & Francisco Arola Sala & 1920 \\
\hline 118. Manual de labores: la labor de gancho & Teresa Köhler de Vizuete & $193 ?$ \\
\hline 122. Manual de labores: la calceta & Teresa Köhler de Vizuete & $193 ?$ \\
\hline 124. El arte del croquis & Víctor Masriera Vila, & 1934 \\
\hline 125. Terremotos y aparatos para registrarlos & Salvador García Franco & 1924 \\
\hline 126. Las razas humanas y su distribución & Alfred C. Haddon & 1924 \\
\hline
\end{tabular}

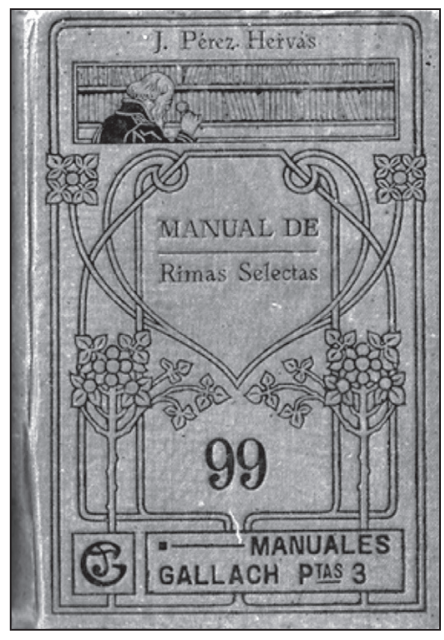

Figura 7. Cubierta del número 99 de Manuales Gallach. Rimas selectas, de Pérez Hervás, colaborador de la editorial y director artístico de la Enciclopedia Espasa. 


\section{Libros de Gallach en la Biblioteca Nacional de Cataluña}

En la Biblioteca de Catalunya los pies de imprenta coinciden con la Biblioteca Nacional de España, y suman 114 títulos referenciados también en cuatro apartados (Tablas 7-10): a) Gallach (14 títulos); b) José Gallach (15 títulos); Instituto Gallach (31); d) Manuales Gallach (54).

a) Gallach

Tabla 7. Libros con el sello Gallach en la Biblioteca Nacional de Cataluña.

\begin{tabular}{|l|c|c|}
\hline \multicolumn{1}{|c|}{ Título } & Autor & Fecha \\
\hline Acumuladores & Francisco Villaverde & $19 ? ?$ \\
\hline Averías en las máquinas eléctricas & Francisco Alsina & $19 ? ?$ \\
\hline Ciencia del arte, La & Víctor Masriera & 1903 \\
\hline España & - & 1911,1913 \\
\hline Gloses sobre cançons populars catalanes per a piano & Onia Farga & 1914 \\
\hline$H^{a}$ de España y de las Repúblicas Latino-Americanas & Alfredo Opisso & 1915 \\
\hline Líneas eléctricas & - & $19 ? ?$ \\
\hline Literatura militar española & Francisco Barado & 1890 \\
\hline Manual de flores artificiales & Dolores Andreu & $190 ?$ \\
\hline Manual de floricultura & José Garzón y Ruiz & $19 ? ?$ \\
\hline Mediciones eléctricas de laboratorio & Ricardo Caro y Anchía & $19 ? ?$ \\
\hline Motores de gas, petróleo y aire & Ricardo Yesares Blanco & $19 ? ?$ \\
\hline Pararrayos y limitadores & Ricardo Caro y Anchía & $19 ? ?$ \\
\hline Reóstatos industriales & Ricardo Caro y Anchía & $19 ? ?$ \\
\hline
\end{tabular}

b) José Gallach

Tabla 8. Libros con el sello José Gallach en la Biblioteca Nacional de Cataluña.

\begin{tabular}{|l|c|c|}
\hline \multicolumn{1}{|c|}{ Título } & Autor & Fecha \\
\hline América Sajona & Emili Huguet de Villar & $19 ? ?$ \\
\hline Amor entre flores & Vicente Terol & $190 ?$ \\
\hline Bases para un nuevo derecho penal & Pedro Dorado Montero & 1902 \\
\hline Educación para niños & Federico Climent Terrer & $19 ? ?$ \\
\hline Enciclopedia moderna catalana & Josep Fiter i Inglés & 1913 \\
\hline Epidemias: defensa moderna, social e individual & Federico Montalvo & 1902 \\
\hline Ex-libris José Gallach & José Triado i Mayol & 1918 \\
\hline Formulario práctico de artes y oficios & Federico Climent Terrer & $192 ?$ \\
\hline Guinea española, La & Ricardo Beltrán y Rózpide & $190 ?$ \\
\hline Horas plácidas para canto y piano & Fernando Villaverde & $19 ? ?$ \\
\hline Manual de mecánica elemental & F. Forner Carratalá & 1910 \\
\hline
\end{tabular}


LA EDITORIAL GALLACHY SU CONTRIBUCIÓN A LA INDUSTRIA CULTURAL ESPAÑOLA...

\begin{tabular}{|l|c|c|}
\hline Medicina doméstica: guía para los primeros auxilios & Alfredo Opisso & $19 ? ?$ \\
\hline Mineralogía & Salvador Calderón y Arana & $19 ? ?$ \\
\hline Remedios vegetales, Los & Alfredo Opisso & $19 ? ?$ \\
\hline Valor social de leyes y autoridades & Pedro Dorado Montero & $19 ? ?$ \\
\hline
\end{tabular}

c) Instituto Gallach

Tabla 9. Libros del Instituto Gallach en la Biblioteca Nacional de Cataluña.

\begin{tabular}{|c|c|c|}
\hline Título & Autor & Fecha \\
\hline Apéndice Gallach: todos los acontecimientos... & - & 1993 \\
\hline Cartas de relación & Hernán Cortés & 1986,1987 \\
\hline Diario de a bordo & Cristoforo Colom & 1992 \\
\hline Fascinante mundo de la historia natural, El & - & 1996 \\
\hline Geografía de España & José Prat Prats & 1994 \\
\hline $\begin{array}{l}\text { Geografía de España: presencia y potencia del suelo y del } \\
\text { pueblo español }\end{array}$ & Ramón Otero Pedrayo & 1955,1956 \\
\hline Geografía universal & - & 1963,2000 (7 ej.) \\
\hline Geografía universal: descripción moderna del mundo & V. Vázquez de Prada & $1931,1963,1975$ \\
\hline Grandes museos de Europa & - & 1999 \\
\hline Historia del almirante & Hernando Colón & 1988 \\
\hline Historia del Arte & - & 1998,2000 \\
\hline Historia de España & - & $1985,1987,2000$ \\
\hline $\begin{array}{l}\text { Historia de España: gran historia general de los pueblos } \\
\text { hispanos }\end{array}$ & Luis Pericot & 1958,1980 \\
\hline Historia de la humanidad & Jacques Pirenne & 1998 \\
\hline Historia natural & - & $\begin{array}{l}1985,1986,1989, \\
1994,1995,1998\end{array}$ \\
\hline $\begin{array}{l}\text { Historia natural: vida de los animales, de las plantas y de } \\
\text { la tierra }\end{array}$ & Ángel Cabrera & 1925,1927 \\
\hline Historia de la II Guerra Mundial y del III Reich & William L. Shirer & 1985 \\
\hline Historia universal & - & 1991 \\
\hline Historia universal: novísimo estudio de la humanidad & - & 1932,1937 \\
\hline Historiadores de Indias & - & 1985,1995 \\
\hline Maravillas de Europa & - & 1998 \\
\hline Mil aspectos de la Tierra y del espacio & - & 1949,1958 \\
\hline Mil figuras de la historia & Jaume Vicens Vivens & 1944 \\
\hline Mil joyas del arte español & - & 1947 \\
\hline Mil obras maestras del arte universal & Alexandre Cirici & 1946 \\
\hline Mil lecciones de la historia & Jaume Vicens Vives & 1951 \\
\hline Mundo de los animales, El & - & 1998 \\
\hline Obras selectas del Instituto Gallach & - & $19 ? ?$ \\
\hline Razas humanas, Las & Pedro Bosch Gimpera & $\begin{array}{c}19 ? ?, 1928,1945 \\
1966,1971,1985 \\
1990,1995\end{array}$ \\
\hline
\end{tabular}




\begin{tabular}{|l|c|c|}
\hline Vida maravillosa de los animales, La. Vertebrados & Antoni Jonch i Cuspinera & 1961,1969 \\
\hline Vida maravillosa de los animales, La. Invertebrados & Carles Bas i Peired & 1961 \\
\hline
\end{tabular}

\section{d) Manuales Gallach}

\section{Tabla 10. Libros de Manuales Gallach en la Biblioteca Nacional de Cataluña.}

\begin{tabular}{|c|c|c|}
\hline Título & Autor & Fecha \\
\hline Contabilidad comercial & José Prats Aymerich & s. f. \\
\hline $\begin{array}{l}\text { Diccionario de argot español: o lenguaje jergal gitano, } \\
\text { delincuente profesional y popular }\end{array}$ & Luis Besses & 1905 \\
\hline 1. Compendio de química general (1) & José Ramón de Luanco & 1903 \\
\hline 3. Física & E. Lozano Ponce León & $190 ?$ \\
\hline 7. Mineralogía & Salvador Calderón y Arana & $19 ? ?$ \\
\hline 10. Armas de guerra & J. Génova e Y & $19 ? ?$ \\
\hline 13. El Sufragio & Adolfo Posada & $19 ? ?$ \\
\hline 16. Armas de caza & J. Génova e Y & 1903 \\
\hline 17. La Guinea española & Ricardo Beltrán y Rozpide & $190 ?$ \\
\hline 18. Meteorología & Augusto T. Arcimis & $190 ?$ \\
\hline 21. Unidades absolutas y unidades prácticas & Carlos Banús y Comas & 1918 \\
\hline 23. Bases para un nuevo derecho penal & Pedro Dorado Montero & 1902 \\
\hline 24. Fuerzas y motores & Mariano Rubió y Bellvé & $19 ? ?$ \\
\hline 25. Gusanos parásitos en el hombre & Marcelo Ribas Mateos & 1918 y 1925 \\
\hline 26. Industrias artológicas: triticultura, molinería, panadería & Narciso Amorós & 1902 \\
\hline 29. Historia de la civilización & Rafael Altamira & 1925 \\
\hline $\begin{array}{l}\text { 30. Las epidemias: defensa moderna, social e individual, } \\
\text { contra las principales }\end{array}$ & Federico Montaldo & 1902 \\
\hline 31. Cristalografía & Lucas Fernández Navarro & 1932 \\
\hline 32. El gramófono moderno (2) & José Arias Gómez & 1931 \\
\hline 38. Valor social de leyes y autoridades & Pedro Dorado Montero & $19 ? ?$ \\
\hline 39. Canales de riego & Josep Zulueta i Gomis & 1900 \\
\hline 40. Arte de estudiar (3) & Mariano Rubio y Bellvé & 1903 \\
\hline 41. Plantas medicinales & Blas Lázaro Ibiza & $19 ? ?$ \\
\hline 42-43. Abc del instalador y montador electricista & Ricardo Yesares Blanco & 1927 \\
\hline $\begin{array}{l}\text { 44. Medicina doméstica: guía para los primeros auxilios } \\
\text { en caso de enfermedades }\end{array}$ & Alfredo Opisso & $19 ? ?$ \\
\hline 45. Contabilidad comercial & José Prats Aymerich & 1910 \\
\hline $\begin{array}{l}\text { 50. Formulario de correspondencia comercial francés-es- } \\
\text { pañol }\end{array}$ & J. Meca Tudela & $192 ?$ \\
\hline 51. Motores de gas, petróleo y aire & Ricardo Yesares Blanco & $19 ? ?$ \\
\hline 58. Pedagogía universitaria & Francisco Giner de los Ríos & 1910 \\
\hline 59. Gallinero práctico & Carlos de Torres & 1915 (2 ej.) \\
\hline 63. Educación de los niños & Federico Climent Terrer & $19 ? ?$ \\
\hline 66. Piedras preciosas: suma de datos y noticias & Marc Jesús Beltrán & 1904 \\
\hline
\end{tabular}


LA EDITORIAL GALLACHY SU CONTRIBUCIÓN A LA INDUSTRIA CULTURAL ESPAÑOLA...

\begin{tabular}{|l|c|c|}
\hline 68. Manual de mecánica & F. Forner Carratalá & 1910 \\
\hline $\begin{array}{l}\text { 69. Los remedios vegetales: tratado popular de las plan- } \\
\text { tas empleadas en medicina (4) }\end{array}$ & Alfredo Opisso & $19 ? ?$ \\
\hline 74. Cerrajería práctica & Eusebio Heras Hernández & $192 ?$ \\
\hline $\begin{array}{l}\text { 84. Manual del naturalista preparador: nuevo tratado teó- } \\
\text { rico práctico para la preparación, disecación }\end{array}$ & Pablo de Areny & 1910 \\
\hline 88. La pirotecnia moderna & Juan Bautista Ferré Vallvé & $19 ? ?$ \\
\hline 94. Derecho internacional & Aniceto Sela y Sampil & 1932 \\
\hline 98. La abeja y sus productos & Vicente Va y Ripa & 1930 \\
\hline 101. El dibujo para todos & Víctor Masriera & $193 ?$ \\
\hline 102. América Sajona & Emilio H. del Villar & $19 ? ?$ \\
\hline 103. Agrimensura & José Ferré Vergés & $19 ? ?$ \\
\hline 104. Estudios de Estética (5) & Alfredo Opisso & 1900 \\
\hline 104. Manual del cajista de imprenta & F. Fábregues & 1933 \\
\hline 105. Manual de floricultura & José Garzón y Ruiz & $19 ? ?$ \\
\hline 106. Manual de flores artificiales & Dolores Andreu & $190 ?$ \\
\hline 107. Formulario práctico de artes y oficios & Federico Climent Terret & $192 ?$ \\
\hline 108-109. Astronomía & Josep Comas i Solá & 1919 \\
\hline 110. El arte de pensar & Alfredo Opisso & $19 ? ?$ \\
\hline 111. Máximas de Epicteto & & $19 ? ?$ \\
\hline 114. Educación cívica & Federico Climent Terrer & 1918 \\
\hline 115. Manual de floricultura (6) & José Garzón Ruiz & $19 ? ?$ \\
\hline 118-119. Manual de labores. La labor de gancho & Teresa Köbler de Vizuete & $19 ? ?$ \\
\hline 122. Manual de labores: la calceta & Teresa Köbler de Vizuete & $19 ? ?$ \\
\hline
\end{tabular}

(1) Edición de 1926 en la BNE; (2) Cambia el título por Artificios de fuego de guerra, 1911-1925, s. a.; (3) Edición de 1911 en la BNE; (4) Cambia el título por Iniciación del empleado de banca,

1934; (5) Dos ejemplares, uno de ellos sin indicación en la ficha de Manuales Gallach; (6) Con el número 115 figura un título distinto en la BNE: Abc de la música.

\section{Libros de Gallach en la biblioteca del Ateneo de Madrid}

En la biblioteca del Ateneo de Madrid se conservan 16 títulos, 11 con el pie de imprenta Instituto Gallach y 5 de la colección Manuales Gallach (Tablas 11 y 12).

a) Instituto Gallach

Tabla 11. Libros del Instituto Gallach en el Ateneo de Madrid.

\begin{tabular}{|l|c|c|}
\hline \multicolumn{1}{|c|}{ Título } & Autor & Fecha \\
\hline Geografía de España (1) & José María Prats & 1993 \\
\hline Geografía Universal: descripción moderna del mundo (2) & Fernando Valls Taberner & 1928 \\
\hline $\begin{array}{l}\text { Historia de España: gran historia general de los pueblos } \\
\text { hispánicos (3) }\end{array}$ & Luis Pericot & 1942 y 1958 \\
\hline Historia Universal: novísimo estudio de la humanidad (4) & Pedro Bosch Gimpera & 1932 \\
\hline
\end{tabular}




\begin{tabular}{|l|c|c|}
\hline Historiadores de Indias (5) & Germán Arciniegas & 1987 \\
\hline $\begin{array}{l}\text { Mil figuras de la historia: nombres ilustres: vidas famosos: } \\
\text { documentos iconográficos (6) }\end{array}$ & Jaime Vicens Vives & 1942 \\
\hline $\begin{array}{l}\text { Mil joyas del arte español: piezas selectas, monumentos } \\
\text { magistrales (7) }\end{array}$ & María Elena Gómez-Moreno & 1947 \\
\hline Mil obras maestras del arte universal(8) & Alexandre Cirici & 1946 \\
\hline Mundo en que vivimos, El & Valentín Vázquez de Prada & 1973 \\
\hline $\begin{array}{l}\text { Razas humanas: su vida, sus costumbres, su historia, su } \\
\text { arte (9) }\end{array}$ & Pedro Bosch & 1928 \\
\hline Vida maravillosa de los animales, La (10) & Antoni Jonch Cuspinera & 1961 \\
\hline
\end{tabular}

(1-5) Un ejemplar de cada uno en la Biblioteca de Cataluña; (6) Dos ejemplares: uno en la BNE y otro en la Biblioteca de Cataluña; (7-8) dos ejemplares en BNE; (9-10) Un ejemplar de cada uno en la Biblioteca de Cataluña.

b) Manuales Gallach

Tabla 12. Libros de Manuales Gallach en el Ateneo de Madrid.

\begin{tabular}{|l|c|c|}
\hline \multicolumn{1}{|c|}{ Título } & Autor & Fecha \\
\hline Documentos mercantiles de uso de fácil transmisión & Francisco Grau Granell & 1903 \\
\hline Manual de hidrología médica & Hipólito Rodríguez Pinilla & $19 ? ?$ \\
\hline 45. Contabilidad comercial (1) & José Prats y Aymerich & 1913 \\
\hline 79. Geografía general (2) & Emilio Hernández del Villa & 1906 \\
\hline 104. Estudio de estética (3) & Alfredo Opios & $19 ? ?$ \\
\hline
\end{tabular}

1) Dos ejemplares, uno en la BNE y otro en la BNC; (2) Un ejemplar en la BNE; (3) Un ejemplar en la BNC.

\section{Libros de Gallach en la biblioteca del Ateneo de Barcelona}

En la Biblioteca del Ateneo se encuentran 8 títulos, de los que sólo uno se imprimió con el sello José Gallach, 5 se realizaron en la etapa del Instituto y se guardan dos ejemplares de la colección de Manuales (Tablas 13-15). Del total se repiten cinco: tres en la Biblioteca Nacional de Cataluña y dos en la Biblioteca Nacional de España.

a) José Gallach

Tabla 13. Libros con el sello José Gallach en el Ateneo de Barcelona.

\begin{tabular}{|c|c|c|}
\hline Título & Autor & Fecha \\
\hline Enciclopedia moderna catalana (1) & Josep Fiter i Inglés & 1913 \\
\hline
\end{tabular}

(1) Ejemplar en la BNC. 
b) Instituto Gallach

Tabla 14. Libros del Instituto Gallach en el Ateneo de Barcelona.

\begin{tabular}{|l|c|c|}
\hline \multicolumn{1}{|c|}{ Título (1) } & Autor & Fecha \\
\hline $\begin{array}{l}\text { Geografía de España: presencia y potencia del suelo y del } \\
\text { pueblo español }\end{array}$ & Ramón Otero Pedrayo & 1955 \\
\hline Geografía Universal: descripción moderna del mundo & Ferran Vals Taberner & 1952 \\
\hline $\begin{array}{l}\text { Historia de España: gran historia general de los pueblos } \\
\text { hispanos }\end{array}$ & Luis Pericot & 1934 \\
\hline Historia Universal: novísimo estudio de la humanidad & Pedro Bosch Gimpera & 1931 \\
\hline $\begin{array}{l}\text { Mil obras maestras del arte universal: maravillas eternas, } \\
\text { creaciones geniales }\end{array}$ & Alexandre Cirici i Pellicer & 1946 \\
\hline
\end{tabular}

(1) De todos estos títulos ejemplares en la BNE y BNC.

c) Manuales Gallach

Tabla 15. Libros de Manuales Gallach en el Ateneo de Barcelona.

\begin{tabular}{|l|c|c|}
\hline \multicolumn{1}{|c|}{ Título } & Autor & Fecha \\
\hline 48. Los centros de contratación & Marc Jesús Beltrán & $190 ?$ \\
\hline 48. Operaciones de bolsa (1) & Marcos Jesús Beltrán & 1931 \\
\hline
\end{tabular}

(1) Un ejemplar en la BNE del título Operaciones de bolsa. Con el mismo número se publicó Los centros de contratación.

\section{Conclusiones}

Tras la investigación realizada, una primera conclusión plantea la necesidad de recuperar y conservar la documentación editorial, entendiendo por tal todos los documentos relacionados con las empresas, tanto los de carácter interno como los generados para la difusión de los productos editoriales, en especial los catálogos.

Como resultado del trabajo se concluye que la editorial Gallach es heredera de Soler, uno de los negocios de estructura familiar que compusieron el tejido de la burguesía catalana, y que más tarde serían base de las primeras sociedades anónimas comerciales, cuya actividad se enmarca en un momento de esplendor y desarrollo de la edición. La editorial fue base para la creación de la prestigiosa Compañía Anónima de Librería, Publicaciones y Ediciones (Calpe), fundada por Nicolás Urgoiti, de la que José Gallach fue gerente y director de la Delegación de Barcelona durante seis años, entre 1918 y 1924, antes de poner en marcha el Instituto de su nombre. 


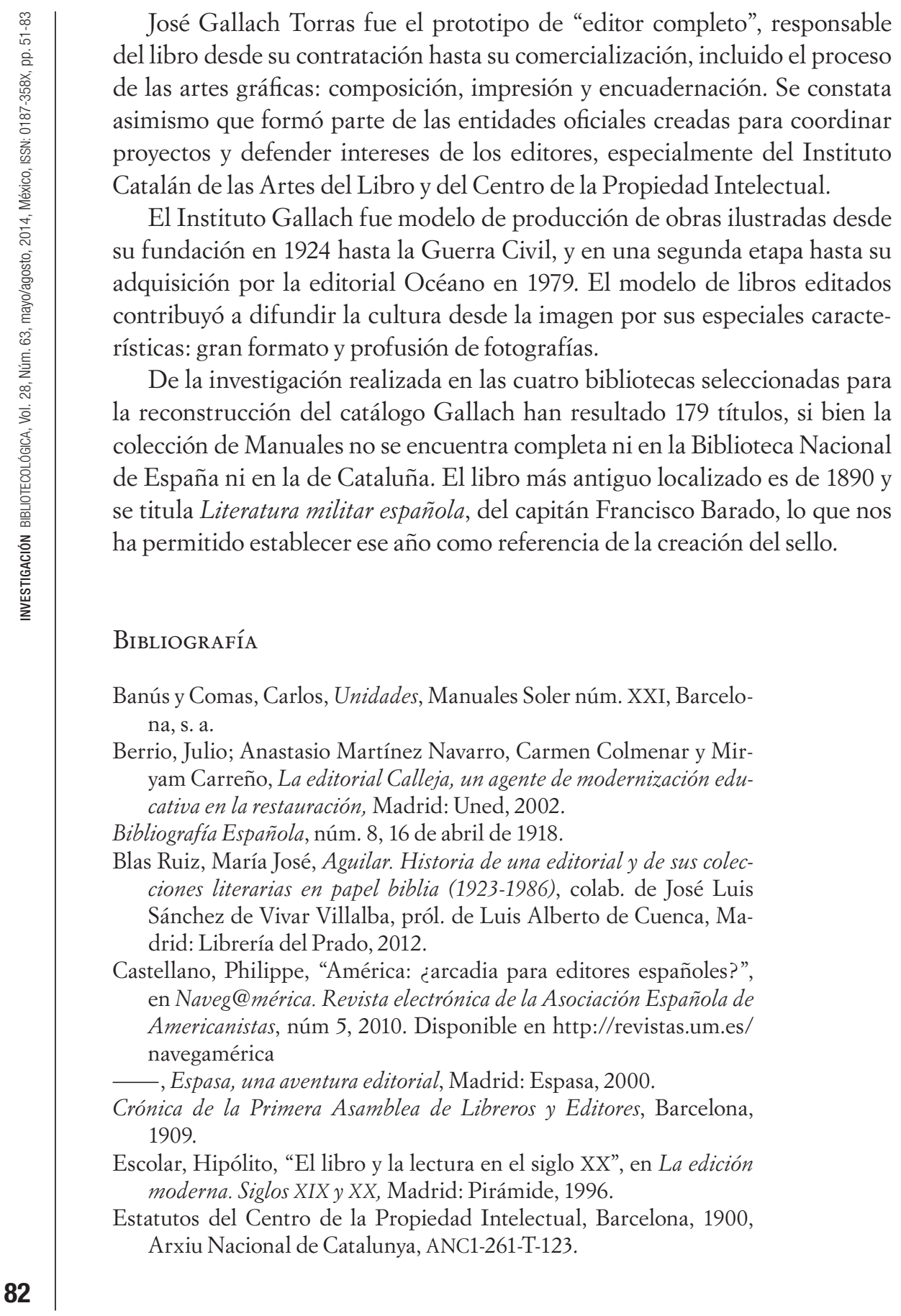


Fernández Rius, Nuria, Pau Audouard, fotògraf retratista de Barcelona De la reputació a l'oblit (1856-1918), tesis Doctoral, Barcelona: Universidad de Barcelona, 2008.

Gallach, "Acción cultural de una empresa editora", en Producciones Selectas, catálogo de la editorial, Barcelona: Gallach, ca. 1930.

Guiral, Antoni, 100 años de Bruguera. De El Gato Negro a Ediciones B, Barcelona: Ediciones B-Grupo Z, 2010.

Infantes, Victor; Françoise López y Jean-Françoise Borrel, Historia de la edición y de la lectura en España, 1472-1914, Madrid: Fundación Germán Sánchez Ruipérez, 2003.

Llanas, Manuel y Antonio Lozano, Seix Barral. Nuestra historia, Barcelona: Seix Barral, 2011.

Martínez Martín, Jesús A. (dir.), Historia de la edición en España (1836-1936), Madrid: Marcial Pons, 2001.

Moret, Xavier, Tiempo de editores. Historia de la edición en España, 1939-1975, Barcelona: Destino, 2002.

Océano Editorial, ¿Quiénes somos? Disponible en: http//:www.oceano.com (Fecha de consulta: 27 de diciembre de 2012).

Sánchez García, Raquel, "La Propiedad Intelectual en La España contemporánea, 1847-1936”, en Hispania, LXII/3, núm. 212, 2002, pp. 993-1019.

Sánchez Vigil, Juan Miguel, La edición en España, Gijón: Trea, 2009. -, Calpe, paradigma editorial, Gijón: Trea, 2005.

Vila-Sanjuán, Sergio, Pasando página, Barcelona: Destino, 2003. Yeves, Juan Antonio, La España Moderna, Madrid: Libris, 2002. 